\title{
CATEGORIAS FREIREANAS NA PRÁXIS
}

\section{FREIREAN CATEGORIES IN PRAXIS}

COIMBRA, Camila Lima ${ }^{1}$

\section{RESUMO}

Este artigo busca algumas categorias da filosofia freireana de educação, ancoradas nas palavras geradas por uma turma de uma disciplina ofertada pela Faculdade de Educação da Universidade Federal de Uberlândia, no segundo semestre de 2017, denominada Princípios Éticos Freireanos. Uma busca de transformar um texto acadêmico em uma reflexão sobre a prática, uma práxis educativa. Assim, torna-se objetivo deste artigo revelar os princípios e as ações que foram construídos nessa práxis. Como romper com uma lógica disciplinar? O que pensar em tempos e espaços universitários tão fragmentados? Quais os desafios para uma práxis freireana? Problematizações que foram perseguidas ao longo deste artigo, justificando as categorias trabalhadas: politicidade, comprometimento, eticidade, democracia e dialogicidade e as relações com o trabalho pedagógico desenvolvido. Uma práxis compartilhada em um exercício docente rigoroso e amoroso, em busca de perspectivas para a formação de professores/as para a Educação Básica.

Palavras-chave: Categorias freireanas; Formação de professores; Currículo; Práxis; Trabalho pedagógico.

\section{ABSTRACT}

This article seeks some categories of the Freirean philosophy of education, based upon the words generated by a class offered by the Faculty of Education of the Federal University of Uberlândia, in the second half of 2017, denominated Freirean Ethical Principles. A quest to transform an academic text into a reflection on practice, an educational praxis. Thus, it is the aim of this article to reveal the principles and actions that were built into that praxis. How does one break with a disciplinary logic? What should one think about university times and spaces that are so fragmented? What are the challenges for a Freirean praxis? Some of the problems that were pursued throughout this article were: politics; commitment; ethics; democracy and dialogue; and the relationship with the pedagogical work developed. A praxis that was shared in a rigorous and loving teaching exercise, in search of perspectives for the formation of Basic Education teachers.

Keywords: Freirean categories; Teacher training; Curriculum; Praxis; Pedagogical work.

\footnotetext{
${ }^{1}$ Doutora em Educação; Professora Associada na Faculdade de Educação da Universidade Federal de Uberlândia - UFU. Pesquisadora do Grupo de Pesquisa Currículo: questões atuais da PUC/SP.
} 


\section{INTRODUÇÃO}

Experiências, saberes e perspectivas individuais e coletivas estão presentes nesta proposta de artigo em que, em um primeiro momento, categorias freireanas são definidas pelo grupo de estudantes que participam de uma práxis educativa na disciplina Princípios Eticos Freireanos. Em um segundo momento, o trabalho pedagógico desenvolvido passa a ser compartilhado, a partir destas experiências e saberes provocados, vivenciados e comprometidos coletivamente. A lógica circular, de pensar e refletir sobre e com a realidade, trouxe sentido para essa práxis. As múltiplas compreensões e momentos foram traduzidos em significados para essa práxis. Os sentimentos, os afetos, a alegria e a esperança foram vivenciados nessa práxis.

Para compreender a dimensão epistemológica deste artigo, busca-se em um vídeo do Projeto Memória (2005) sobre a experiência de Freire na Secretaria Municipal de Educação em São Paulo, um fragmento da fala de Freire em que ele explica que o que fez não foi um método, mas uma filosofia. Esse é um princípio que norteia este artigo, extrair a filosofia de Freire, nomeando as categorias fundantes para a práxis educativa: conceitos e uma experiência se entrecruzam.

Nesse sentido, objetiva-se, com este artigo, trabalhar com essas categorias que emergiram como palavras geradoras na tentativa de demarcar princípios que fundamentam uma práxis educativa da disciplina criada pelo Núcleo de Didática ND, da Faculdade de Educação, da Universidade Federal de Uberlândia denominada "Princípio Éticos Freireanos" para os cursos de licenciatura.

Para o aprofundamento das categorias freireanas, torna-se fundamental a compreensão da não neutralidade da educação e principalmente, da "quebra" do poder do/a educador/a existente numa lógica de educação bancária, pois quando Freire diz que os/as educandos/as têm o direito e dever de terem seus sonhos, mesmo que sejam diferentes dos sonhos dos educadores, essa fala tem uma densidade importante para a definição das categorias freireanas, como se estivéssemos apreendendo da obra de Freire quais são os princípios para uma práxis educativa? Como podemos reinventar as categorias freireanas em uma práxis educativa?

Inicialmente, é importante destacar o significado da leitura de mundo (sociedade) e da educação em Freire, pois, para ele, essa é a condição para compreender essa relação.

É por isso que o problema real que se nos coloca não é o de insistir numa teimosia sem sucesso - a de afirmar a neutralidade impossível da educação, mas reconhecendo sua politicidade, lutar pela postura ético-democrática de acordo com a qual educadoras e educadores, podendo e devendo afirmar-se em seus sonhos, que são políticos, se impõem, porém: 


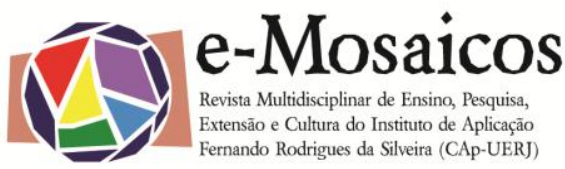

DOI: $10.12957 /$ e-mosaicos.2017.31162

a) deixar claro aos educandos que há outros sonhos contra os quais, por várias razões a ser explicadas, os educadores ou as educadoras podem até lutar;

b) que os educandos têm o direito de ter o dever de ter os seus sonhos também, não importa que diferentes ou opostos aos de seus educadores (FREIRE, 1993b, p. 21).

Anuncia-se, assim, a primeira categoria: politicidade. A educação como uma ação política e o sonho como atitude para educandos/as e ducadores/as. Sabe-se que o conceito de politicidade foi sendo alterado e mal interpretado nas políticas públicas neoliberais, especialmente pelo Projeto de Lei $n^{\circ} 867$, de 2015, denominado de Programa Escola sem Partido, que associa politicidade ao que chamam de doutrinamento político e ideológico ${ }^{2}$. Porém, o sentido que tentamos resgatar na educação freireana, a partir dessa categoria, configura-se na compreensão de que o processo educativo tem um caráter político que precisa ser identificado, ou seja, "não há nem jamais houve prática educativa em espaço e tempo nenhum de tal maneira neutra, comprometida apenas com ideias preponderantemente abstratas e intocáveis" (FREIRE, 1992, p.78). Ou seja, até mesmo o programa denominado Escola sem Partido não é neutro. Entende-se, assim, que

é na diretividade da educação, esta vocação que ela tem, como ação especificamente humana, de endereçar-se até sonhos, ideais, utopias e objetivos, que se acha o que venho chamando politicidade da educação. A qualidade de ser política, inerente à sua natureza (FREIRE, 1997, p. 110).

Somos seres históricos, constituídos/as de tudo e todos que passaram pela nossa trajetória de vida. Tudo que me constitui, me faz, me delineia, em termos de princípios e valores e em termos de ação concreta. Somos seres culturais.

Outra categoria importante, nesse contexto, é o comprometimento. Uma perspectiva freireana requer uma atitude comprometida com a realidade social que nos cerca. "O compromisso seria uma palavra oca, uma abstração, se não envolvesse a decisão lúcida e profunda de quem o assume. Se não se desse no plano do concreto" (FREIRE, 1983, p. 15). Essa categoria está localizada na indissociabilidade freireana entre as ideias e a ação, pois a primeira condição para que um ser possa assumir um ato comprometido está na nossa capacidade de agir e refletir. "É exatamente esta capacidade de atuar, operar, de transformar a realidade de acordo com finalidades propostas pelo homem, a qual está associada sua capacidade de refletir, que o faz um ser da práxis" (FREIRE, 1983, p.17).

\footnotetext{
${ }^{2}$ Projeto de Lei no 867, de 2015. http://www.camara.gov.br/sileg/integras/1317168.pdf . Acesso em $31 / 10 / 2017$.
} 
Diminuir a distância entre o que dizemos e o que fazemos, ou seja, "ensinar exige a corporeificação das palavras pelo exemplo" (FREIRE, 1997, p. 38). Um dos saberes necessários à prática educativa serve de âncora para a primeira categoria: politicidade, sustentáculo de uma concepção freireana na educação, também se relaciona à necessária articulação entre a teoria e a prática na atividade e formação docente.

Freire complementa (1997, p. 38): "a prática docente crítica, implicante do pensar certo, envolve o movimento dinâmico, dialético, entre o fazer e o pensar sobre o fazer". Essa atitude tem, necessariamente, pela característica humana do ser comprometido, uma concepção e uma prática que nutrem uma escolha: educação para quem? Não há como discutir quando restringimos o direito à educação.

A terceira categoria apresenta-se como um conceito, talvez ainda abstrato na sociedade em que vivemos, porém fundante para uma educação progressista: eticidade, a ética nas relações humanas sob a forma de respeito com o outro. "O que sobretudo me move a ser ético é saber que, sendo a educação, por sua própria natureza, diretiva e política, eu devo, sem jamais negar o meu sonho ou minha utopia aos educandos, respeitá-los" (FREIRE, 1992, p.78). Educar significa respeito. Respeito pelo outro, com o outro. Esse outro não é um ser abstrato, mas o sujeito concreto que vive, sofre, ama e se move no compromisso com a transformação social.

\begin{abstract}
Nas minhas relações com os outros, que não fizeram necessariamente as mesmas opções que fiz, no nível da política, da ética, da estética, da pedagogia, nem posso partir de que devo 'conquistá-los', não importa a que custo, nem tampouco temo que pretendam 'conquistar-me'. É no respeito às diferenças entre mim e eles ou elas, na coerência entre o que faço e o que digo, que me encontro com eles ou com elas. $E$ na minha disponibilidade à realidade que construo a minha segurança, indispensável à própria disponibilidade. É impossível viver a disponibilidade à realidade sem segurança mas é impossível também criar a segurança fora do risco da disponibilidade (FREIRE, 1997, p. 135).
\end{abstract}

Arriscar, disponibilizar, conquistar, construir são verbos que transitam na definição da ética enquanto uma ação de respeito com o outro. Colocar-se no lugar do outro apresenta-se como uma situação necessária para a compreensão do conceito práxico dessa categoria.

A democracia, na vivência e concepção freireana, é a quarta categoria que sustenta esta concepção de educação. "Minha questão não é negar a politicidade e a diretividade da educação, tarefa de resto impossível de ser convertida em ato, mas, assumindo-as, viver plenamente a coerência entre a minha opção democrática e a minha prática educativa, igualmente democrática" (FREIRE, 1992, p.79). 
Democracia e liberdade são condições indispensáveis para a leitura de mundo freireana. Uma sociedade democrática implica, necessariamente, em uma sociedade de direitos, de humanização, de compreensão do sujeito e do outro, implica no diálogo, condição para a relação entre os sujeitos fazedores de história. "A prática preconceituosa de raça, de classe, de gênero ofende a substantividade do ser humano e nega radicalmente a democracia" (FREIRE, 1997, p.17).

A quinta categoria: dialogicidade, o diálogo com respeito às diferenças de ideias e posições, quanto a necessidade humana de comunicação social.

E que é diálogo? É uma relação horizontal de A com B. Nasce de uma matriz crítica e gera criticidade. Nutre-se do amor, da humildade, da esperança, da fé, da confiança. Por isso, só o diálogo comunica. E quando os dois pólos do diálogo se ligam assim, com amor, com esperança, com fé um no outro, se fazem críticos na busca de algo. Instala-se, então, uma relação de simpatia entre ambos. Só aí há comunicação (FREIRE, 1967, p. 107).

A partir dessa categoria dialogicidade, que traduz o sentimento deste artigo, é que se tem a compreensão de que em uma concepção de práxis já defendida, é importante "viver a abertura respeitosa aos outros e, de quando em vez, de acordo com o momento, tomar a própria prática de abertura ao outro objeto da reflexão crítica, deveria fazer parte da aventura docente" (FREIRE, 1997, p. 153).

A perspectiva de compreender o uno e o diverso, o eu e o outro em uma relação dialógica, faz-se importante enxergar as relações imbricadas entre o local e universal numa relação ética e, ao mesmo tempo, dialética.

Para mim vem sendo difícil, impossível mesmo, entender a interpretação de meu respeito ao local, como negação do universal (...) Creio que o fundamental é deixar claro ou ir deixando claro aos educandos esta coisa óbvia: o regional emerge do local tal qual o nacional surge do regional e o continental do nacional como o mundial emerge do continental (FREIRE, 1997, p. 87).

Por isso, a necessidade do respeito ao contexto cultural. O respeito, então, ao saber popular implica necessariamente o respeito ao contexto cultural. A localidade dos educandos/as é o ponto de partida para o conhecimento que eles/as vão criando do mundo. "'Seu' mundo, em última análise é a primeira e inevitável face do mundo mesmo" (FREIRE, 1992, p. 86).

Para Freire, a relação pedagógica entre educador/a e educando/a deve ser centrada no diálogo. A valorização e o respeito ao conhecimento do/a educando/a 
DOI: $10.12957 /$ e-mosaicos.2017.31162

são fundamentais para a produção do conhecimento e para uma educação libertadora. Uma forma de conscientização com a valorização de sua dignidade humana e a busca de justiça em nossa sociedade.

Sustenta-se, assim, uma concepção de educação freireana em que esse movimento histórico-dialético dos sujeitos faz e se refaz na prática social, na convivência com o outro, pois é no exercício do diálogo que herdamos e reinventamos a cultura.

A consciência do mundo, que viabiliza a consciência de mim, inviabiliza a imutabilidade do mundo. A consciência do mundo e a consciência de mim me fazem um ser não apenas no mundo, mas com o mundo e com os outros. Um ser capaz de intervir no mundo e não só de a ele se adaptar. É neste sentido que mulheres e homens interferem no mundo enquanto os outros animais apenas mexem nele. É por isso que não apenas temos história, mas fazemos a história que igualmente nos faz e que nos torna, portanto, históricos (FREIRE, 2000, p. 40).

Essa capacidade de intervenção no mundo significa, nessa concepção freireana, a capacidade humana de ser e agir em nossa realidade: a práxis. Significa compreender a comunicação, o diálogo como a possibilidade concreta de transformar o mundo, de transformar a realidade, por isso seres históricos. A categoria do diálogo sustenta, assim, a práxis, a relação dialética entre ação (prática) e reflexão (teoria) mediadora entre mundo e a consciência, como uma relação importante para que o diálogo ocorra efetivamente.

Cinco categorias foram anunciadas: politicidade, comprometimento, eticidade, democracia, dialogicidade e práxis que assegurem a dignidade humana, a liberdade e a justiça social. Pensar em uma educação progressista implica sentir, pensar e agir sobre: o pressuposto político da educação (A favor de quem? Para quem?), o compromisso e a ética das relações (Como? Quais valores?), a democracia (Com quem?) e o diálogo (Para que?) em uma relação a partir da realidade concreta.

A compreensão dessas categorias freireanas e a necessidade de sua materialização, fizeram da disciplina de Princípios Éticos Freireanos uma práxis educativa. São complementares, indissociáveis, articulados, gravitam e circulam em torno da filosofia freireana de educação, pois se realiza na práxis humana, na potencialidade humana de pensar e agir.

\section{UMA PRÁXIS EDUCATIVA}

A partir dessas reflexões e com a proposição de contribuir nesse campo formativo, o Núcleo de Didática (ND) entendeu a necessidade de oferta de disciplinas mais específicas para a formação de professores, sendo uma delas, Princípios Éticos 
DOI: 10.12957/e-mosaicos.2017.31162

Freireanos. Essa disciplina já fazia parte do currículo do Curso de Pedagogia do campus Pontal da Universidade Federal de Uberlândia (UFU) em Ituiutaba, que tem seu Projeto Pedagógico de Curso (PPC) inspirado em princípios freireanos. Assim, o ND criou a disciplina para os Cursos de Uberlândia, atendendo aos princípios, necessidades e demandas da instituição.

A disciplina foi construída para, como o próprio nome diz, apresentar os princípios éticos freireanos no campo da educação brasileira. A partir das teorias críticas de currículo, dentro da pedagogia progressista, em uma perspectiva libertadora, contribuir para a compreensão do perfil profissional e humano na formação de professores. A sua criação foi pensada para qualquer curso de graduação da UFU, com o enfoque na contribuição de Paulo Freire para a formação de professores no Brasil.

Assim, em 13 de abril de 2015, o ND encaminhou a solicitação de criação da disciplina, no âmbito da UFU. O processo interno de criação demorou 2 (dois) anos. Sendo esta criada por meio da Resolução no 07/2016 do Conselho de Graduação, em 10 de julho de 2016. Em sua Ficha de Disciplina, apresenta a seguinte ementa:

Concepção de homem, de mundo e de realidade na perspectiva freireana. As relações entre docência e discência. Biografia de Paulo Freire. Fundamentos éticos do agir humano com a educação. Relação do homem como fazedor de história e de sua práxis social. Os pressupostos da concepção libertadora da educação. A reflexão crítica sobre a prática. Princípios éticos da formação humana e da sociedade em Paulo Freire.

A partir deste norte e dos objetivos também anunciados na Ficha, tais como: compreender a importância dos princípios freireanos para a educação brasileira; compreender o princípio do respeito à diversidade como um pressuposto ético essencial para a atuação docente em uma escola que se pretende democrática e inclusiva; contribuir para a reflexão dos profissionais da educação para que trabalhem com diferentes metodologias de ensino, coerentes com o respeito à diversidade física, ideológica, psíquica, étnico-cultural e socioeconômica presentes no cotidiano escolar.

A primeira turma da disciplina iniciou-se no segundo semestre de 2017, ancorada nesta ementa e objetivos e passa a ser o conteúdo dessa práxis.

No primeiro dia de aula, fizemos o reconhecimento do grupo. Aprendemos um pouquinho uns sobre os outros. Fizemos o movimento da escuta. Mas antes disso, escrevi sobre as minhas expectativas...

Meu sonho sempre foi trabalhar com uma disciplina que não fosse obrigatória e sim escolhida pelos estudantes. Inicio hoje a 
materialização de um sonho, a concretização de um inédito viável, a alegria de ser professora, a busca em ser uma educadora, a esperança na formação. Que tenhamos a oportunidade de aprender junto, por meio do diálogo, com Freire nos ajudando a reinventar nossas leituras de mundo. Que tenhamos a sensibilidade em ler muitas e tantas formas o outro e nós mesmos, com linguagens, gestos e afetos. Que tenhamos a possibilidade de romper a rigidez da academia e possamos sentir. Enfim, que estejamos juntos/juntas e que façamos o nosso melhor para transformar esse mundo em um lugar humano, solidário e ético (Camila).

A disciplina teve um movimento, criado e desenvolvido pelo grupo de estudantes que fizeram sua matrícula neste componente curricular. 0 caminho teórico-metodológico foi traçado coletivamente, por meio de decisões e argumentos da realidade destes/as estudantes. Muitos deles/as já fizeram a disciplina de Didática Geral, nas licenciaturas. A partir do dia da escuta, traçamos as diretrizes do nosso caminho, com um norte procurado por todos/as: de que essa disciplina fosse possibilitadora de ampliar o conhecimento de todos/as sobre a teoria freireana, mas e junto com ela, a criação de um espaço, na academia, em que pudéssemos sentir, vivenciar, experienciar. Traduzir Paulo Freire das palavras para a ação. Esse foi o nosso desafio coletivo: buscar a coerência entre a teoria e a prática.

Decidimos por desenvolver a disciplina em 4 (quatro) momentos: 0 encontro dos aprendentes: quem somos e o que queremos?, como primeiro momento. 0 segundo momento, denominamos de Conceitos importantes; o terceiro momento chamamos de Reconstruindo conceitos. O quarto momento como de Sínteses necessárias. Talvez a explicação ficasse melhor em forma de círculos que se movimentam e se interagem o tempo todo.

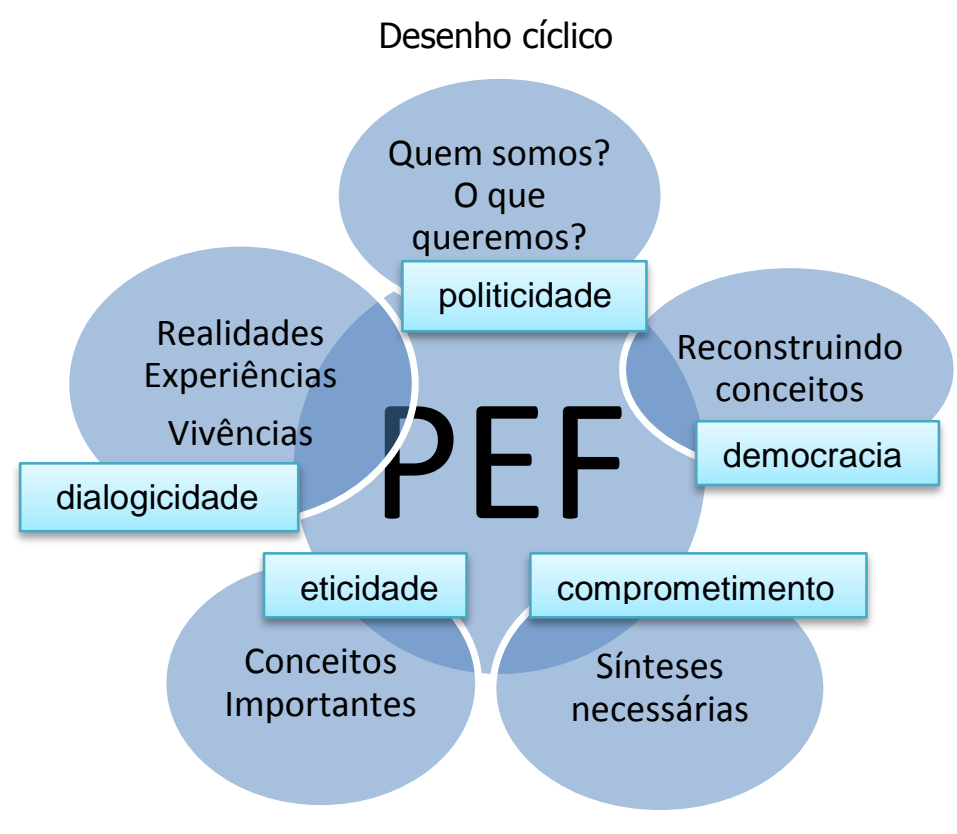


Nenhum momento é tão pontual assim. Eles se entrecruzam, produzem intersecções, voltam e revoltam sobre aquilo que parece significativo e importante para aprendizagem. A sala de aula é circular, o movimento circular pretende configurar a nossa concepção de mundo, de aprendizagem e ensino. Se pudéssemos colocar essa figura em movimento seria a melhor descrição de como esses processos interagem.

Para o primeiro momento, foram utilizadas as primeiras três semanas, em que as perguntas foram: o que conheço e o que gostaria de conhecer sobre Paulo Freire? Quais perguntas tenho sobre o que sei e o que mais pretendo conhecer? A partir desse movimento, construímos nossos desenhos-identidade, nos reconhecemos no Grupo e chegamos a algumas palavras geradoras: politicidade, práxis, dialogicidade, eticidade, democracia, homem/mulher, conscientização, libertação, inédito viável, alfabetização de adultos, educação popular, educação bancária, autonomia, formação de professores, academia/universidade, cultura, escola/comunidade, visão/leitura de mundo. Ainda no primeiro momento, construímos a linha do tempo do Paulo Freire até o exílio e de sua bibliografia. Fizemos um mapeamento das obras em seu momento histórico. Estas obras foram apresentadas a todos/as e a partir dela, compreendemos o itinerário, a vida e a obra de Paulo Freire para que as escolhas pudessem ser feitas.

No segundo momento, Conceitos importantes foram trabalhados a partir das palavras geradoras. A cada dia, dois conceitos eram tratados no Círculo, na roda de conversa, entremeados às nossas histórias, às poesias, músicas, dados da realidade que chegavam por meio de cada um/a. Nesse movimento, foi possível que cada um/a fosse buscando o seu interesse de leitura: qual livro de Paulo Freire gostaria de ler, frente ao que já conheceu? Não houve uma referência única para a leitura, mas cada um/a escolheu o seu livro frente aos seus desejos e necessidades. A única exigência da mediadora é que fosse do próprio Paulo Freire.

No terceiro momento: Reconstruindo conceitos, fomos debatendo as palavras geradoras e criando nossas reinvenções. Convidamos uma professora aposentada da UFU, professora Gercina Santana Novais, que foi secretária de educação do município em uma administração do Partido dos Trabalhadores para trazer algumas de nossas palavras geradoras. Criamos palavras, em um exercício de rever os conceitos que consideramos fundantes em uma práxis educativa progressista. Das palavras que foram trazidas ao grupo, acrescentamos: coragem, respeito, compreensão, leitura, reciprocidade, perseverança, escuta, fronteira, vazio, humanização, empatia. Com essas, criamos: leituta, perseveragem, vaziar, es-vaziar, compromicidade, emanizar. Momentos de troca importantes foram criados a partir dessas reinvenções.

No quarto momento, denominado Sínteses necessárias, cada estudante faz a socialização de sua leitura e a respectiva materialização da mesma. Os livros escolhidos foram: Educação e Mudança; Pedagogia do Oprimido; Política e educação; Educação na cidade; Professora sim, tia não: cartas a quem ousa ensinar; Educação 
DOI: $10.12957 /$ e-mosaicos.2017.31162

como prática da liberdade; Pedagogia da Esperança: um reencontro com a Pedagogia do Oprimido; A importância do ato de ler; Medo e ousadia: o cotidiano do Professor; Pedagogia da Autonomia: saberes necessários à prática educativa.

Como forma de materializar esse diálogo, para todos os momentos, criamos as várias possibilidades, a partir de cada um/a e com o que o grupo traçou como objetivo.

\section{Um caderno de registro: Ensinar é... aprendi o quê?}

As perguntas mobilizadoras para essa atividade foram: 0 que aprendemos? Quais valores? Quais atitudes? O que importa? O que me move? A ideia é que nesse registro, possamos escrever/registrar os valores, as aprendizagens que aprendemos por meio dos exemplos e das pessoas com quem tivemos a oportunidade de conviver. Um princípio para esse registro foi a compreensão de nossos saberes que são oriundos de nossas experiências, vivências, decepções, amores, rancores, de nossas trajetórias pessoais, sociais e culturais.

\section{Um caderno de Registro das aulas}

Inicialmente seria em dupla e depois passamos para um exercício individual de registro livre. Não precisava ser a descrição de todas as atividades que aconteceram na aula, mas a forma como cada um/a sentiu aquela aula. A riqueza dos registros de cada um/a e sua forma de viver a disciplina.

Músicas. Reflexões. Paixões. Vivências expressas de diversas formas que podemos registrar. $O$ escutar e o olhar sensíveis foram 0 princípio. Cada participante registrou a seu modo, com sua ternura e sua cor, a partir do que cada tarde de quarta-feira significava. Foram registros sérios, alegres, encantadores, representativos de um grupo que foi se constituindo. Cada momento desse, respeitado como único no meio do universo de coisas que eu gostaria de conviver e ver ainda em minha relação comprometida com o educar. Cada palavra, gesto, emoção e canção registrados sob olhar diversos em busca de nos tornarmos "mais gente" (Camila).

\section{Nosso bonsai: inspirações}

Levei um Bonsai no primeiro dia. Trouxe o trecho de uma entrevista de Freire em que ele diz:

Eu não posso desistir da esperança porque eu sei, primeiro, que ela é ontológica. Eu sei que não posso continuar sendo humano se eu faço desaparecer de mim a esperança e a briga por ela. A esperança não é uma doação. Ela faz parte de mim como o ar que respiro. Se não houver ar, eu morro. Se não houver esperança, não tem por que continuar o histórico. A esperança é a história, entende? No momento em que você definitivamente perde a esperança, você cai no 
e-Mosaicos - Revista Multidisciplinar de Ensino, Pesquisa, Extensão e Cultura do Instituto de Aplicação Fernando Rodrigues da Silveira (CAp-UERJ)

DOI: $10.12957 /$ e-mosaicos.2017.31162

imobilismo. E aí você é tão jabuticabeira quanto a jabuticabeira (FREIRE, 1993) ${ }^{3}$.

Iniciamos, desde a primeira semana a esperança em não nos tornarmos jabuticabeiras. $O$ rodízio de cuidados ao longo do semestre com o bonsai, pode significar o que esquecemos de fazer com o/a outro/a. Ao final, vamos plantar o bonsai na UFU com uma placa criada e produzida por nós da primeira Turma de Princípios Éticos Freireanos da UFU. Cada um que leva, traz uma informação sobre o bonsai para o nosso Círculo de cultura.

\section{Programa de rádio: aprendizagens freireanas}

Ao final da disciplina, criamos a ideia de produzir e gravar um ou mais podcast com as aprendizagens realizadas ao longo do semestre.

\section{REFLEXõES FINAIS}

Incorporar os sujeitos como fazedores de história também um desafio da disciplina.

Fazendo-se e refazendo-se no processo de fazer história, como sujeitos e objetos, mulheres e homens, virando seres da inserção no mundo e não da pura adaptação ao mundo, terminaram por ter no sonho também um motor da história. Não há mudança sem sonho como não há sonho sem esperança. (...) Não posso entender os homens e as mulheres, a não ser mais do que simplesmente vivendo, histórica, cultural e socialmente existindo, como seres fazedores de seu caminho que, ao fazê-lo, se expõem ou se entregam ao caminho que estão fazendo e que assim os refaz também (FREIRE, 1992, p. 91-97).

Sustenta-se, assim, uma concepção de educação freireana em que os processos educativos trazem novos significados tanto para a professora quanto para os/as estudantes.

Na linha progressista, ensinar implica, pois, que os educandos, em certo sentido, penetrando o discurso do professor, se apropriem da significação profunda do conteúdo sendo ensinado. O ato de ensinar, vivido pelo professor ou professora, vai desdobrando-se, da parte dos educandos, no ato de estes conhecerem o ensinado. Por sua vez, o(a) professor(a) só ensina em termos verdadeiros na medida em que conhece o conteúdo que ensina, quer dizer, na medida em que

\footnotetext{
3 FREIRE, Paulo. Nós podemos reinventar o mundo. Entrevista. In: Revista Nova Escola, 1993. Disponível em https://novaescola.org.br/conteudo/4937/arquivo-paulo-freire-nos-podemos-reinventaro-mundo . Acesso em 11/11/2017.
} 
se apropria dele, em que o apreende. Neste caso, ao ensinar, o professor ou a professora re-conhece o objeto já conhecido. (...) Por isso, ensinar é um ato criador, um ato crítico e não mecânico. A curiosidade do(a) professor(a) e dos alunos, em ação, se encontra na base do ensinar-aprender (FREIRE, 1992, p. 81).

Como temos demonstrado, o fundamento que norteia essa disciplina transcende uma concepção restrita de educação, identificando-a como uma importante ação humana em um processo de construção/conscientização para uma sociedade menos excludente.

Uma educação humanizada é o caminho pelo qual homens e mulheres podem se tornar conscientes da sua presença no mundo. $A$ maneira como atuam e pensam quando desenvolvem todas as suas capacidades, tomando em consideração as suas necessidades. Mas também as necessidades e aspirações dos outros (CIRIGLIANO, 2001, p. 95).

Pensar com o outro, a partir do outro e fazer desse, o sentido para a formação de professores foi o mobilizador desse processo em que, a cada momento, criamos novas formas de pensar e fazer os princípios éticos freireanos no campo da educação e da sala de aula.

\section{REFERÊNCIAS BIBLIOGRÁFICAS}

CIRIGLIANO, Gustavo F. J. Por uma pedagogia do excluído; reflexões de um velho professor. In: FREIRE, Ana Maria Araújo. (Org.) A pedagogia da libertação em Paulo Freire. São Paulo: Editora UNESP, 2001.

FREIRE, Paulo. Educação como prática da liberdade. Rio de Janeiro: Paz e Terra, 1967.

. Pedagogia do Oprimido. Rio de Janeiro: Paz e Terra, 1974.

. Educação e Mudança. Rio de janeiro: Paz e Terra, 1983.

. Pedagogia da Esperança: um reencontro com a Pedagogia do Oprimido. Rio de Janeiro: Paz e Terra, 1992.

. Professora sim, tia não: cartas a quem ousa ensinar.16ed, São Paulo: Olhos d'água, 1993a.

. Política e educação: ensaios. São Paulo: Cortez, 1993b. 
. Pedagogia da Autonomia: saberes necessários à prática educativa. 29ed.

São Paulo: Paz e Terra, 1997.

. Pedagogia da Indignação: cartas pedagógicas e outros escritos. São Paulo:

Editora Unesp, 2000.

\& SHOR, Ira. Medo e ousadia: o cotidiano do professor. Rio de Janeiro, Paz

e Terra, 1987 (5ed, 1995), 224p. (Educação e Comunicação)

SEQUEIROS, Leandro. Educar para a solidariedade: projeto didático para uma nova cultura de relações entre os povos. Porto Alegre: Artes Médicas Sul, 2000.

Recebido em 15 de outubro de 2017. Aceito em 10 de novembro de 2017. 